\title{
Pertumbuhan dan produksi Okra (Abelmoschus esculentus) dengan berbagai pemupukan organik diperkaya batuan fosfat
}

\author{
(Growth and yield of Okra (Abelmoschus esculentus) as affected by organic fertilizers \\ enriched by rock phosphate) \\ I. Pranata, D.R. Lukiwati, W. Slamet \\ Agroecotechnology, Faculty of Animal and Agricultural Sciences, Diponegoro University \\ Tembalang Campus, Semarang 50275 - Indonesia \\ Corresponding E-mail: imampranataagr@gmail.com
}

\begin{abstract}
ABSTRAK
Penelitian bertujuan untuk mengetahui pengaruh pemupukan organik diperkaya batuan fosfat terhadap pertumbuhan dan produksi okra. Penelitian menggunakan rancangan acak kelompok monofaktor dengan perlakuan pupuk T1. Batuan fosfat (BP), T2. Kompos azolla pinnata, T3. Pupuk kandang (pukan) sapi, T4. Pukan kambing, T5. Pukan ayam, T6. Kompos Azolla pinnata+BP, T7. Pukan sapi+BP, T8. Pukan kambing+BP, T9. Pukan ayam+BP, diulang sebanyak 3 kali. Parameter yang diamati tinggi tanaman, jumlah daun, jumlah buah, berat segar buah dan produksi bahan kering. Data dianalisis ragam dan uji lanjut dengan Duncan's Multiple Range Test (DMRT). Hasil penelitian menunjukkan bahwa perlakuan pukan ayam diperkaya BP menghasilkan tinggi tanaman $154,00 \mathrm{~cm}$ dan jumlah daun 22,56 helai lebih tinggi dibanding perlakuan lainnya. Perlakuan kompos azolla, pukan sapi, kambing, dan ayam diperkaya BP menghasilkan berat buah segar lebih tinggi dibanding kompos dan pukan tanpa diperkaya BP. Perlakuan kompos dan pukan diperkaya BP maupun tidak, menghasilkan jumlah buah yang tidak berbeda nyata. Pukan kambing+BP dan pukan ayam+BP menghasilkan bahan kering masingmasing 107,79 dan 105,53 g nyata lebih tinggi dibanding perlakuan lainnya. Perlakuan batuan fosfat tunggal nyata lebih rendah untuk semua parameter dibanding perlakuan lainnya.

Kata kunci : Batuan fosfat, okra, pertumbuhan, produksi tanaman, pupuk organik
\end{abstract}

\begin{abstract}
The research aimed to study the effect of organic fertilizer reached by rock phosphate (RP) on the growth and yield of okra. The experiment was assigned in monofactor randomized block design with treatment the types of organic fertilizer, T1. Rock phosphate (RP), T2. Azolla pinnata compost, T3. ow manure, T4. goat manure, T5. poultry manure, T6. Azolla pinnata compost $+\mathrm{RP}, \mathrm{T} 7$. cow manure $+\mathrm{RP}$, T8. goat manure $+R P$, T9. poultry manure $+R P$. Each treatments was repeated three times. Parameters measured were high, leaf number, fruit number, fresh fruit weight and dry matter production. Data were subjected to anova and followed by DMRT. The result showed that T9 gave high plant $154.00 \mathrm{~cm}$ and leaf number 22.56 higher compared with another treatments. The treatments of azolla compost, cow manure, goat manure, and pultry manure with reached by rock phosphate or not, gave non significant of fruit number. The goat manure+RP and poultry manure+RP gave the dry matter 107.79 and $153.53 \mathrm{~g}$ higher compare with another treatments. The treatment of single rock phosphate gave the lower to all parameters compared with another treatments.
\end{abstract}

Keywords : Growth, okra, organic fertilizer, rock phosphate, yield

\section{PENDAHULUAN}

Okra merupakan salah satu komoditas sayur yang bergizi tinggi sehingga mulai banyak dikenal dan dibudidayakan oleh masyarakat. Beberapa negara telah menggunakan okra sebagai tanaman sayuran sekaligus obat untuk beberapa penyakit antara lain disentri, iritasi lambung, iritasi usus 
besar, radang tenggorokan, penyakit gonore (Lim, 2012), dan dibetes mellitus (Amin, 2011). Produksi okra dipengaruhi oleh tingkat kesuburan tanah. Pupuk anorganik masih digunakan untuk memenuhi kebutuhan nutrisi okra karena kandungan unsur hara tinggi, larut dalam air dan mudah diabsorbsi oleh tanaman. Namun, harganya mahal sehingga kurang ekonomis dan penggunaan secara terus menerus berdampak negatif pada sifat fisik, kimia, dan biologi tanah.

Pemanfaatan pupuk organik kurang maksimal karena memerlukan kuantitas yang besar dan kandungan unsur hara rendah, sehingga respon tanaman relatif lambat. Beberapa sumber pupuk organik yang dapat digunakan adalah pupuk kandang (pukan) sapi, pukan kambing, pukan ayam, dan kompos azolla. Pupuk kandang (pukan) sapi mengandung $\mathrm{N}, \mathrm{P}_{2} \mathrm{O}_{5}, \mathrm{~K}_{2} \mathrm{O}$, dan $\mathrm{C}$ organik; 1,$30 ; 0,58 ; 2,15 ;$ dan $13,5 \%$ dengan rasio $\mathrm{C} / \mathrm{N}$ sebesar 11 (Adeniyan et al., 2011). Pukan kambing mengandung $\mathrm{N}, \mathrm{P}_{2} \mathrm{O}_{5}, \mathrm{~K}_{2} \mathrm{O}$, dan $\mathrm{C}$ organik; 1,17; 1,10; 2,36; dan 15,1 39,3\% dengan rasio $\mathrm{C} / \mathrm{N} 33$ (Cho et al., 2016). Pukan ayam mengandung $\mathrm{N}, \mathrm{P}_{2} \mathrm{O}_{5}, \mathrm{~K}_{2} \mathrm{O}$, dan C-organik; 2,21; 2,$98 ; 2,05$; dan 15,1 dengan rasio $\mathrm{C} / \mathrm{N}$ dan 7 (Adeniyan et al., 2011). Azolla mengandung $4-5$ $\% \mathrm{~N}$ berdasarkan bahan kering, berat kering, bahan organik, kalsium, fosfor masing-masing 4,$12 ; 75,73 ; 2,58 ; 0,26 \%$ (Halder dan Kheroar, 2013; Chrryl et al., 2014). Kualitas pupuk organik perlu diperkaya untuk meningkatkan kandungan hara, salah satunya fosfor $(\mathrm{P})$ yang bersumber dari batuan fosfat. Batuan fosfat (BP) memiliki kelarutan yang rendah jika diaplikasikan secara langsung ke tanah. Peningkatan kelarutan BP dapat dilakukan dengan teknologi dekomposisi.

Dekomposisi merupakan proses perombakan bahan organik menjadi mineral yang dapat dijadikan sebagai sumber nutrisi bagi tanaman. Selama dekomposisi berlangsung menghasilkan asam-asam organik, misalnya asam oksalat, nitrat, sitrat, glukonat, suksinat, asetat (Rashid et al., 2004). Asam-asam tersebut mampu menngkatkan efisiensi kelarutan P (Khan dan Sharif, 2012). Perlakuan bahan organik diperkaya BP mampu menghasilkan produksi buah lebih tinggi dibanding perlakuan bahan organik tunggal (Majundar et al., 2007). Peningkatan bahan kering tanaman secara signifikan terjadi akibat aplikasi bahan organik diperkaya BP (Awaad et al., 2009). Kombinasi kompos diperkaya BP meningkatkan konsentrasi ketersediaan $\mathrm{P}$ tanah (mikroba pelarut $\mathrm{P}$ dan $\mathrm{NaHCO}_{3}-\mathrm{Pi}$ ) dan produksi $\mathrm{P}$ tanaman (Verma, 2013).

Penelitian bertujuan untuk mengetahui pengaruh pemupukan pupuk organik diperkaya batuan fosfat pada pertumbuhan dan produksi okra.

\section{MATERI DAN METODE}

\section{Materi}

Penelitian telah dilaksanakan pada tanggal 29 Januari sampai dengan 5 Mei 2017 di lahan pertanian desa Kreyo, Pemalang; Laboratorium Ekologi dan Produksi Tanaman, Laboratorium Fisiologi dan Pemuliaan Tanaman, Fakultas Peternakan dan Pertanian, Universitas Diponegoro. Bahan yang digunakan benih okra varietas ever lucky, tanaman Azolla pinnata, pupuk kandang (pukan) sapi, pukan kambing, pukan ayam dan batuan fosfat.

\section{Metode}

Penelitian dilaksanakan dengan pembuatan pupuk kompos azolla, pukan sapi, pukan kambing, dan pukan ayam yang diperkaya batuan fosfat (BP) dengan dosis $60 \mathrm{~kg} \mathrm{P} / \mathrm{ha}$ dan tanpa BP kemudian diperam selama 4 minggu. Dosis pupuk kompos/kandang 10 t/ha. Kemudian nutrisi pupuk dan kimia tanah dianalisis (Tabel 1). Petak percobaan dibuat dengan ukuran $3 \times 2 \mathrm{~m}$, pupuk diberikan dua hari sebelum tanam, benih okra disemai selama 2 minggu. Setelah itu, okra ditanam dengan jarak tanam 50x50 $\mathrm{cm}$ (populasi 24 tanaman/petak).

Perawatan okra dilakukan dengan cara didangir dan disiram. Pegendalian hama, penyakit, dan gulma dilakukan jika diperlukan. Panen okra pertama kali pada umur 35 hari setelah tanam, yaitu buah dengan panjang $9-11 \mathrm{~cm}$ (Aguiar et al., 2015). Panen pada dua minggu pertama dilakukan 3 hari sekali, kemudia memasukki minggu ketiga sampai keempat, panen dilakukan 1 - 2 hari sekali bergantung pada panjang buah yang telah siap panen. Jumlah buah okra diakumulasi dari pertama panen sampai panen terakhir.

Parameter yang diamati adalah tinggi tanaman, jumlah daun, jumlah buah, berat segar buah, dan produksi bahan kering. 
Tabel 1. Hasil Analisis Kimia Tanah Awal Penelitian

\begin{tabular}{lll}
\hline \hline Unsur & Kadar & Kriteria *) \\
\hline $\mathrm{N}$ total $(\%)$ & 0,43 & Sedang \\
$\mathrm{P}_{2} \mathrm{O}_{5}(\mathrm{ppm})$ & 21 & Rendah \\
$\mathrm{K}_{2} \mathrm{O}(\mathrm{ppm})$ & 50 & Sedang \\
$\mathrm{pH}$ & 6,8 & Agak netral \\
$\mathrm{C}$-organik $(\%)$ & 2,3 & Sedang \\
Rasio C/N & 5,35 & Normal \\
\hline
\end{tabular}

Keterangan : *) Departemen Pertanian, 1983.

\section{Rancangan Penelitian dan Anilisis Data}

Rancangan yang digunakan adalah Rancangan Acak Kelompok monofaktor. Perlakuan yang diberikan adalah T1. Batuan fosfat (BP), T2. Kompos azolla pinnata, T3. Pupuk kandang (pukan) sapi, T4. Pukan kambing, T5. Pukan ayam, T6. Kompos azolla pinnata+BP, T7. Pukan sapi+BP, T8. Pukan kambing+BP, T9. Pukan ayam+BP, diulang sebanyak 3 kali. Data dianalisis ragam dan uji Duncan's Multiple Range Test (DMRT) pada taraf $\alpha=5 \%$.

\section{HASIL DAN PEMBAHASAN}

\section{Pertumbuhan Tanaman Okra}

Hasil analisis ragam menunjukkan bahwa perlakuan pupuk organik berpengaruh nyata terhadap tinggi tanaman dan jumlah daun okra $(\mathrm{P}<0,05)$. Berdasarkan Tabel 2 dan Ilustrasi 1 dapat diketahui bahwa perlakuan pukan ayam diperkaya BP (T9) menghasilkan tinggi tanaman $154,00 \mathrm{~cm}$ nyata lebih tinggi dibanding perlakuan lainnya $(\mathrm{P}<0,05)$. Perlakuan pukan kambing+BP (T8) tidak berbeda nyata terhadap pukan sapi+BP (T7), kompos azolla+BP (T6), dan pukan tanpa diperkaya (T5, T4, dan T3) masing-masing 136,$04 ; 132,79 ; 128,75 ; 137,75 ; 132,58$; dan 126,88 cm. Perlakuan BP tunggal (T1) menghasilkan tinggi tanaman $107,97 \mathrm{~cm}$ nyata lebih rendah dibanding perlakuan lainnya $(\mathrm{P}<0,05)$. Pukan ayam mampu melarutkan $\mathrm{P}$ lebih tinggi dibanding pukan sapi, pukan kambing, dan kompos azolla sehingga diduga meningkatkan kelarutan BP (Arifah, 2013). Hara P berperan dalam pembelahan dan perkembangan sel, transfer energi, menstimulasi perkembangan akar dan meningkatkan kekuatan batang. Ketersediaan $\mathrm{P}$ yang cukup mengarahkan pertumbuhan tinggi tanaman yang lebih tinggi (Hog-Jensen et al., 2002).

Tabel 2. Rerata Tinggi Tanaman dan Jumlah Daun Okra pada Berbagai Pupuk Organik

\begin{tabular}{lcc}
\hline \multicolumn{1}{c}{ Jenis Pupuk } & Tinggi Tanaman & Jumlah Daun \\
\hline & $\ldots \ldots . \mathrm{cm} \ldots \ldots . .$. & $\ldots .$. helai..... \\
T1. Batuan Fosfat (BP) & $107,97^{\mathrm{d}}$ & $11,60^{\mathrm{d}}$ \\
T2. Kompos azolla & $124,88^{\mathrm{c}}$ & $16,37^{\mathrm{c}}$ \\
T3. Pukan sapi & $126,88^{\mathrm{bc}}$ & $17,39^{\mathrm{bc}}$ \\
T4. Pukan kambing & $132,58^{\mathrm{bc}}$ & $17,75^{\mathrm{bc}}$ \\
T5. Pukan ayam & $137,75^{\mathrm{b}}$ & $19,29^{\mathrm{b}}$ \\
T6. Kompos azolla+BP & $128,75^{\mathrm{bc}}$ & $17,50^{\mathrm{bc}}$ \\
T7. Pukan sapi+BP & $132,79^{\mathrm{bc}}$ & $19,21^{\mathrm{bc}}$ \\
T8. Pukan kambing+BP & $136,04^{\mathrm{b}}$ & $20,75^{\mathrm{b}}$ \\
T9. Pukan ayam+BP & $154,00^{\mathrm{a}}$ & $22,56^{\mathrm{a}}$ \\
\hline
\end{tabular}

Keterangan : superskrip berbeda pada kolom yang sama menunjukkan perbedaan nyata $(\mathrm{P}<0,05)$ 


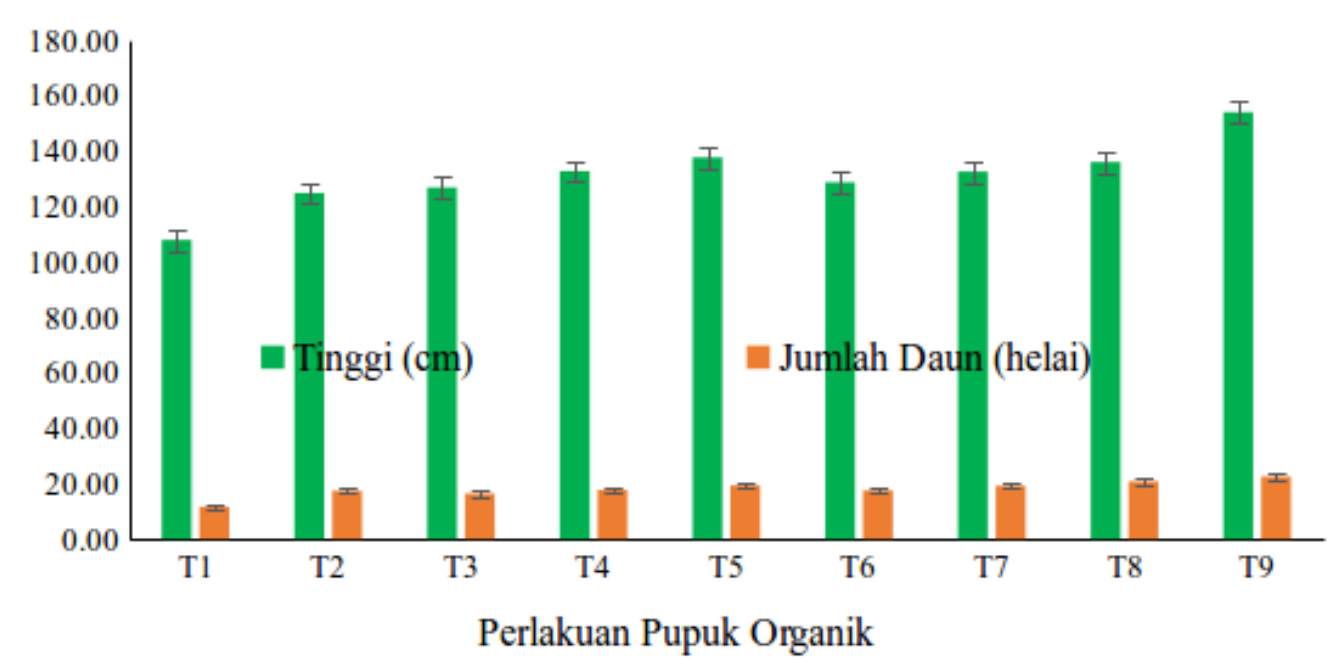

Ilustrasi 1. Tinggi Tanaman dan Jumlah Daun Okra Pada Berbagai Jenis Pupuk Organik

Pertumbuhan vegetatif terutama tinggi tanaman dipengaruhi oleh ketersediaan unsur hara dalam tanah, terutama $\mathrm{N}$ dan $\mathrm{P}$. Pukan ayam mengandung $\mathrm{N}$ dan $\mathrm{P}$ realtif lebih tinggi dibanding pupuk kandang lainnya. Unsur $\mathrm{N}$ memiliki peran utama untuk merangsang pertumbuhan vegetatif tanaman secara keseluruhan, khususnya pertumbuhan batang yang mampu memacu pertumbuhan tinggi tanaman (Suryati et al., 2015). Selain itu, pukan ayam mempunyai kandungan lignin dan selulosa yang lebih rendah dibanding pukan sapi dan kambing, sehingga proses penguraian bahan organik berlangsung lebih cepat (Arifah, 2013). Semakin cepat penguraian bahan organik, maka ketersediaan hara bagi tanaman juga lebih cepat.

Berdasarkan Tabel 2 dan Ilustrasi 1 dapat diketahui bahwa perlakuan pukan ayam diperkaya BP (T9) menghasilkan jumlah daun 22,56 helai nyata lebih tinggi dibanding perlakuan lainnya $(\mathrm{P}<0,05)$. Perlakuan pukan kambing diperkaya BP (T8) tidak berbeda nyata terhadap pukan sapi+BP (T7), kompos azolla+BP (T6), dan pukan tanpa diperkaya (T5, T4, dan T3) masing-masing 20,75; 19,$21 ; 17,50 ; 19,29 ; 17,75$; dan 17,39 helai. Perlakuan BP tunggal (T1) menghasilkan jumlah daun 11,60 helai nyata lebih rendah dibanding perlakuan lainnya $(\mathrm{P}<0,05)$. Perlakuan pukan ayam+BP (T9) menghasilkan jumlah daun okra nyata lebih tinggi dibanding perlakuan lainnya karena pukan ayam memiliki nutrisi yang lebih tinggi dan lebih mudah terurai. Pukan ayam mengandung lignin dan selulosa lebih rendah, lebih cepat terurai dibanding pukan sapi dan kambing sehingga lebih mudah diabsorbsi oleh akar tanaman (Adil et al., 2006). Penelitian lain menunjukkan bahwa pemupukan dengan dosis yang sama 10 ton/ha, pukan ayam memberikan jumlah daun nyata lebih tinggi dibanding pukan sapi dan kambing (Ali et al., 2014). Perlakuan pukan ayam+BP (T9) memiliki kandungan hara $\mathrm{N}$ dan $P$ relatif lebih tinggi dibanding pupuk lainnya, hal ini menyebabkan proses pembentukan daun lebih cepat. Ketersediannya $\mathrm{N}$ dan $\mathrm{P}$ yang cukup meningkatkan pertumbuhan organ-organ tanaman, salah satunya proses pembentukan daun (Maghfoer et al., 2013).

\section{Produksi Okra}

Berdasarkan hasil analisis ragam perlakuan pupuk organik berpengaruh nyata terhadap jumlah dan berat segar buah okra $(\mathrm{P}<0,05)$. Pengaruh perlakuan pupuk organik terhadap produksi jumlah buah, berat segar buah, dan bahan kering okra tercantum pada Tabel 3 sebagai berikut :

Tabel 3 menunjukkan bahwa perlakuan kompos azolla, pukan sapi, kambing, dan ayam diperkaya BP maupun tidak menghasilkan jumlah buah yang tidak berbeda nyata $(\mathrm{P}<0,05)$. Perlakuan BP tunggal (T1) menghasilkan jumlah buah 15,92 buah/tanaman nyata lebih rendah dibanding perlakuan lainnya. Aplikasi BP secara langsung belum mampu memenuhi kebutuhan $\mathrm{P}$ 
Tabel 3. Rerata Jumlah buah, Berat Segar Buah, dan Bahan Kering Okra pada Berbagai Pupuk Organik

\begin{tabular}{|c|c|c|c|}
\hline Jenis Pupuk & Jumlah Buah & Berat Segar Buah & $\begin{array}{c}\text { Produksi Bahan } \\
\text { Kering }\end{array}$ \\
\hline T1. Batuan Fosfat (BP) & $\begin{array}{c}\text {....buah/tanaman.... } \\
15,92^{\mathrm{c}}\end{array}$ & $\begin{array}{c}\ldots . . \mathrm{g} / \operatorname{tanaman} . . . . \\
163,94^{\mathrm{d}}\end{array}$ & 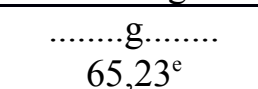 \\
\hline T2. Kompos azolla & $24,17^{\mathrm{b}}$ & $248,92^{\mathrm{c}}$ & $82,99^{\mathrm{d}}$ \\
\hline T3. Pukan sapi & $25,79^{\mathrm{b}}$ & $296,60^{\mathrm{b}}$ & $72,99^{\mathrm{c}}$ \\
\hline T4. Pukan kambing & $27,63^{\mathrm{ab}}$ & $317,69^{b}$ & $97,99^{\mathrm{b}}$ \\
\hline T5. Pukan ayam & $27,67^{\mathrm{ab}}$ & $318,17^{\mathrm{b}}$ & $97,01^{\mathrm{b}}$ \\
\hline T6. Kompos azolla+BP & $28,51^{\mathrm{ab}}$ & $359,21^{\mathrm{a}}$ & $97,47^{\mathrm{b}}$ \\
\hline T7. Pukan sapi+BP & $27,96^{\mathrm{ab}}$ & $352,28^{\mathrm{a}}$ & $95,58^{\mathrm{b}}$ \\
\hline T8. Pukan kambing+BP & $29,49^{\mathrm{a}}$ & $371,60^{\mathrm{a}}$ & $105,53^{\mathrm{a}}$ \\
\hline T9. Pukan ayam + BP & $29,77^{\mathrm{a}}$ & $375,06^{\mathrm{a}}$ & $107,79^{\mathrm{a}}$ \\
\hline
\end{tabular}

Keterangan : superskrip berbeda pada kolom yang sama menunjukkan perbedaan nyata $(\mathrm{P}<0,05)$

tanaman sehingga produksi buah tidak maksimal. Pupuk BP memiliki kelarutan rendah, aplikasi BP pada tanah yang bereaksi netral sampai agak masam tidak mampu melarutkan $\mathrm{P}$ yang tersedia bagi tanaman sehingga produksi buah rendah (Supriyadi et al., 2014). Ketersediaan P yang rendah menghambat absorbsi hara $\mathrm{N}$ oleh akar tanaman. Semakin tinggi konsentrasi $\mathrm{P}$ di dalam tanah, maka serapan $\mathrm{N}$ juga meningkat (Fahmi et al., 2010). Nitrogen menjadi salah satu bahan fotosintesis yang berpengaruh secara langsung terhadap produksi tanaman. Nitrogen berperan penting dalam menghasilkan asimilat yang diperlukan untuk memproduksi buah, kekurangan $\mathrm{N}$ dapat menurunkan produksi buah (Ayissa dan kebebe, 2011).

Berdasarkan Tabel 3 dapat diketahui bahwa perlakuan pukan ayam+BP (T9) menghasilkan berat buah segar 359,21 g/tanaman tidak berbeda nyata dengan kompos azolla dan pukan yang diperkaya batuan fosfat (T8, T7, dan T6) masingmasing 352,28; 371,60, dan 375,06 g/tanaman $(\mathrm{P}<0,05)$. Aplikasi kompos azolla, pukan sapi, kambing, dan ayam diperkaya BP (T9, T8, T7, T6) menghasilkan berat segar buah nyata lebih tinggi dibanding perlakuan lainya $(\mathrm{P}<0,05)$. Perlakuan BP (T1) menghasilkan berat segar buah 163,94 $\mathrm{g} /$ tanaman nyata lebih rendah dibanding perlakuan lainnya. Perlakuan kompos azolla dan semua pukan diperkaya BP (T9, T8, T7, T6) menyediakan hara $\mathrm{P}$ lebih tinggi dibanding pukan tunggal karena penambahan BP ke dalam proses dekomposisi mampu meningkatkan kelarutan BP. Perlakuan bahan organik diperkaya BP mampu menghasilkan produksi buah lebih tinggi dibanding perlakuan bahan organik tunggal (Majundar et al., 2007). Asam-asam organik dalam proses dekomposisi bahan organik meningkatkan kelarutan BP menjadi $\mathrm{P}$ tersedia bagi tanaman sehingga mampu meningkatkan produksi buah (Khan dan Sharif, 2012). Unsur hara $\mathrm{P}$ berperan penting dalam reproduksi tanaman, ketersediaan P yang cukup mengarahkan produksi tanama yang lebih tinggi.

Tabel 3 menunjukkan bahwa masing-masing perlakuan kompos azolla, pukan sapi, kambing, dan ayam diperkaya BP (T9, T8, T7, T6) menghasilkan berat kering 107,79; 105,53; 95,58; $97,47 \mathrm{~g}$ nyata lebih tinggi $(\mathrm{P}<0,05)$ dibanding kompos dan semua pukan tanpa diperkaya BP (T5, T4, T3, T2). Perlakuan BP tunggal menghasilkan bahan kering 65,23 g nyata lebih rendah dibanding perlakuan lainnya $(\mathrm{P}<0,05)$. Pupuk BP yang ditambahkan ke dalam dekomposisi bahan organik kelarutannya meningkat dibandingkan BP yang diaplikasikan secara langsung. Asam-asam organik pada saat dekomposisi bahan organik gugus fungsional yang sangat reaktif ($\mathrm{COOH} /$ fenolik dan -OH/alkoholik) yang miliki peran penting meningkatkan ketersediaan $\mathrm{P}$ dalam tanah (Haynes dan Mokolobate, 2001). Kompos dan pukan diperkaya BP memberikan konstribusi 
hara yang lebih tinggi dibanding pukan dan kompos tunggal sehingga mampu meningkatkan berat kering tanaman. Bahan kering total diperoleh pada perlakuan bahan organik diperkaya batuan fosfat dibanding perlakuan bahan organik tunggal (Majundar et al., 2007). Penelitian lain juga menunjukkan bahwa peningkatan bahan kering tanaman secara signifikan terjadi akibat aplikasi bahan organik diperkaya BP (Awaad et al., 2009).

Perlakuan T1 nyata lebih rendah dibanding perlakuan lainnya karena pupuk BP yang diaplikasikan langsung ke tanah memiliki tingkat kelarutan yang sangat rendah sehingga ketersediaan $\mathrm{P}$ terbatas, akibatnya okra tidak tumbuh maksimal. Ketersediaan $\mathrm{P}$ yang cukup mampu meningkatkan akumulasi bahan kering tanaman, kekurangan $\mathrm{P}$ akan menghambat laju pertumbuhan tanaman (Turuko dan Mohammed, 2014). Ketersediaan $P$ yang rendah mengurangi absorbsi hara $\mathrm{P}$ oleh akar sehingga akumulasi bahan tidak maksimal. Penyerapan $\mathrm{P}$ tanaman meningkatkan pembentukan biomassa dan berat kering tajuk tanaman (Hermawan et al., 2014). Oleh sebab itu, aplikasi BP akan lebih efektif apabila ditambahkan ke dalam proses dekomposisi bahan organik untuk meningkatkan kelarutannya.

\section{KESIMPULAN}

Berdasarkan penelitian yang telah dilakukan dapat disimpulkan bahwa perlakuan pukan ayam diperkaya BP mampu meningkatkan tinggi tanaman dan jumlah daun. Perlakuan kompos azolla, pukan sapi, kambing, dan ayam diperkaya BP menghasilkan berat buah segar lebih tinggi dibanding kompos dan pukan tanpa diperkaya BP. Perlakuan kompos dan pukan diperkaya BP maupun tidak, belum mampu meningkatkan produksi jumlah buah okra. Pukan kambing dan pukan ayam diperkaya BP mampu meningkatkan bahan kering okra. Perlakuan batuan fosfat tunggal nyata lebih rendah untuk semua parameter.

\section{DAFTAR PUSTAKA}

Adeniyan, O.N., A.O. Ojo, O.A. Akinbode, and J.A. Adediran. 2011. Comparative study on different organic manures and NPK fertilizer for improvement of soil chemical properties and dry matter yield of maiza in two different soils. J. of Soil Scie. and Envi. Management 2 (1) : $9-13$.

Adil, W.H., N. Sunarlim, dan I. Roostika. 2006. Pengaruh tiga jenis pupuk nitrogen terhadap tanaman sayuran. Biodiversitas 7 (1) : 77 80.

Aguiar, J.L., M. Mcgiffen, E. Natwick, and E. Takele. 2011. Okra Production in California. University of California, California.

Ali, M.B., H.I. Lakun, S.M. Sani, and H.M. Adamu. 2014. Effect of organic manure and sowing date on the growth and yield of okra (Abelmoschus esculentus L. Moench) in Samaru, Nigeria. Int. J. of Agro. and Agric. Research 5 (5) : 111 - 117.

Amin, I.M. 2011. Nutritional properties of Abelmoschus esculentus as remedy to manage diabetes mellitus : A literatire review. International Conference on Biomedical Enginering and Technologi. IACSIT Press, Singapore.

Arifah, S.M. 2013. Aplikasi macam dan dosis pupuk kandang pada tanaman kentang. Jurnal GAMMA 8 (2) : $80-85$.

Awaad, M.S., A.A. Rashad, and M.A. Bayoumi. 2009. Effect of farmyard manure combined with some phosphate sources on the productivity of canola plants grown on a sandy soil. Research J. of Agric. and Biol. Scie. 5 : 1176 - 1181 .

Ayissa, T. and F. Kebebe. 2011. Effect of nitrogenous fertilizer on the growth and yield of cotton (Gossypium hirsutum L.) varieties in middle Awash, Ethiopia. J. of the Drylands 4 (1) : $248-258$.

Cho, W., B. Ravinsran, J.J. Kim, K. Jeong, D.J. Lee, and D. Choi. 2016. Nutrient status and phytotoxity analysis of goat manure discharged from farm in South Korea. Environ. Tech. 38 (9) : 1191 - 1199.

Chrryl, D.M., R.M.V. Prasad, S. 
JagadeeswaraRao, P. Jayalaxmi, and D.S. Kumar. 2014. A study on the nutritive value of Azolla pinnata. Livestock Research Int. 2 (1) : $13-15$.

Fahmi, A., Syamsudin, S.N.H. Utami, dan B. Radjagukguk. 2010. Pengaruh interaksi hara nitrogen dan fosfor terhadap pertumbuhan tanaman jagung (Zea mays L.) pada tanah regosol dan latosol. Berita Biologi 10 (3) : $297-304$.

Halder, D. and S. Kheron. 2013. Mineralization and avaibility of Azolla and Cyanobacteria biomass nutrient in rice soil. J. of Agric. Scie. and Tech. $3: 728-789$.

Haynes, R.J. and M.S. Mokolobate. 2001. Amelioration of $\mathrm{Al}$ toxicity and $\mathrm{P}$ deficiency in acid soils by addition of organic residues: A critical review of the phenomenon and the mechanisms involved. Nutr. Cycl Agroecosyst $59: 47$ - 63.

Hermawan, A., Sabaruddin, Marsi, R. Hayati, and Warsito. 2014. P use Efficiency by corn (Zea mays L.) on ultisol due to application of coal fly ash-chicken manure mixture. Agrivita 36 (2) : $146-152$.

Hog-Jensen, H., J. Schjoerring, J.F. Soussana. 2002. The influence of phosphorus deficiency on growth and nitrogen fixation of white clover plants. Ann. Bot. 90 : 745 753.

Khan, M. and M. Sharif. 2012. Solubility enhancment of phosphorus from rock phosphate through composting with poultry litter. Sarhad J. Agric. 28 (3) : 415 - 420.

Lim T. K. 2012. Edible Medicinal and NonMedicinal Plants : Fruits. Springer Science and Business Media B.V. 3 pp. 160.
Maghfoer, M.D., R. Soelistyono, and N. Herlina. 2013. Response of eggplant (Solanum melongena L.) to combination of inorganicorganic N and EM4. Agrivita 35 (3) : 296 303.

Majundar, B., M.S. Venkatesh, K. Kumar, and Patiram. 2007. Effect of rockphosphate, superphosphate and thei mixtures with FYM on soybean and soil-P pools in a typic hapludalf of Meghalaya. J. Indian Soc. of Soil Scie. 55 (2) : $167-174$.

Rashid M., S. Khalil, N. Ayub, S. Alam and F. Latif. 2004. Organic acids production and phosphate solubilization by phosphate solubilizing microorganisms (PSM) under in vitro condition. Pak. J. Biol. Sci. 7 (2): 187-196.

Supriyadi, S. Hartati, dan A. Aminudin. 2014. Kajian pemberian pupuk $\mathrm{P}$, pupuk mikro dan pupuk organik terhadap serapan dan hasil kedelai (Glycine max L.) varietas kaba di inseptol Gunung Gajah Klaten. Jurnal Ilmu Ilmu Pertanian 29 (2) : $81-86$.

Suryati, D., Sampurno, dan E. Anom. 2015. Uji beberapa konsentrasi pupuk azolla (Azolla pinnata) pada pertumbuhan bibit kelapa sawit (Elaeis guineensis Jacq.) di pembibitan utama. JOM faperta 2 (1) : 1 13.

Turuko, M. and A. Mohammed. 2014. Effect of different phosphorus fertilizer rates on growth, dry matter and yield components of common bean (Phaseolus vulgaris L.). World J. of Agric. Research 2 (3) : 88 - 92.

Verma, S.L. 2013. Effect of compost on soil phosphorus avaibility. Thesis. School of Agriculture, Food and Wine, the university of Adelaide. 